Our findings are consistent with those from recent prospective studies that have shown a strong association between high circulating concentrations of insulin-like growth factor I in adulthood and subsequent risk of premenopausal, but not postmenopausal, breast cancer. ${ }^{19}{ }^{20}$

In public health terms, if the findings were real, large birth size would be responsible for only a small proportion of the total number of cases of breast cancer in any population as the incidence at premenopausal ages is low. The association of larger size at birth with an increased risk of premenopausal breast cancer should be considered in light of its opposite association with ischaemic heart disease, ${ }^{12}$ a much more common condition.

In summary, our results provide strong evidence that there is real association between birth size and risk of breast cancer at premenopausal ages and that fetal growth rate, rather than size at birth alone, may be the aetiological relevant factor.

\section{Contributors: see bmj.com}

Funding: The Uppsala birth cohort study was established on grants provided by the UK Medical Research Council (No 9322050), the Swedish Council for Social Research (No 94/0157), and the Swedish Medical Research Council (No 5446). This work was conducted within the MRC Cooperative on "Life-course and trans-generational influences on disease risk" (G9819083).

Competing interests: None declared.

1 Trichopoulos D. Hypothesis: does breast cancer originate in utero? Lancet 1990;335:939-40.

2 Vatten LJ, Maehle BO, Lund Nielsen TI, Tretli S, Hsieh C-C, Trichopoulos D, et al. Birthweight as a predictor of breast cancer: a case-control study in Norway. Br J Cancer 2002;86:89-91.

3 Michels KB, Trichopoulos D, Robins JM, Rosner BA, Manson JE, Hunter DJ, et al. Birthweight as a risk factor for breast cancer. Lance 1996:348:1542-6.

4 De Stavola BL, Hardy R, Kuh D, dos Santos Silva I, Wadsworth M, Swerdlow AJ. Birthweight, childhood growth and risk of breast cancer in a British cohort. BrJ Cancer 2000;83:964-8.
5 Ekbom A, Trichopoulos D, Adami HO, Hsieh CC, Lan SJ. Evidence of prenatal influences on breast cancer risk. Lancet 1992;340:1015-8.

6 Sanderson M, Williams MA, Malone KE, Stanford JL, Emanuel I, White E, et al. Perinatal factors and the risk of breast cancer. Epidemiology $1996 ; 7: 34-7$

7 Innes K, Byers T, Schymura M. Birth characteristics and subsequent risk for breast cancer in very young women. Am J Epidemiol 2000;152:1121-8.

8 Titus-Ernstoff L, Egan KM, Newcomb PA, Ding J, Trentham-Dieta A, Greenberg ER, et al. Early life factors in relation to breast cancer risk in postmenopausal women. Cancer Epidemiol Biomark Prev 2002;11:207-10.

9 Ekbom A, Hsieh CC, Lipworth L, Adami HQ, Trichopoulos D. Intrauterine environment and breast cancer risk in women: a population-based study. J Natl Cancer Inst 1997;89:71-6.

10 Ekbom A, Erlandsson G, Hsieh C, Trichopoulos D, Adami HO, Cnattingius S. Risk of breast cancer in prematurely born women. J Natl Cancer Inst 2000;92:840-1.

11 Leon DA. Fetal growth and later disease: epidemiological evidence from Swedish cohorts. In: Shaughn O'Brien PM, Wheller T, Barker DJ, eds. Fetal programming: influences on development and disease in later life. London: Roval College of Obstetricians and Gynaecologists Press, 1999.

12 Leon DA, Lithell HO, Vägerö D, Koupilová I, Mohsen R, Berglund L, et al. Reduced fetal growth rate and increased risk of death from ischaemic heart disease: cohort study of 15000 Swedish men and women born 1915-29. BMJ 1998;317:241-5.

13 Marubini E, Valsecchi MG. Analysing survival data from clinical trials and observational studies. New York: Wiley 1994

14 Sørensen HT, Sabroe S, Rothman KJ, Gillman M, Steffensen FH, Fischer $\mathrm{P}$, et al. Birth weight and length as predictors for adult height. Am J Epide miol 1999;149:726-9.

15 Tuvemo T, Cnattingius S, Jonsson B. Prediction of male adult stature using anthropometric data at birth: a nationwide population-based study. Pediatric Res 1999;46:491-5.

16 Van den Brandt PA, Spiegelman D, Yaun SS, Adami HO, Beeson L, Folsom AR, et al. Pooled analysis of prospective cohort studies on height, weight, and breast cancer risk. Am J Epidemiol 2000;152:514-27.

17 Endogenous Hormones and Breast Cancer Collaborative Group. Endogenous sex hormones and breast cancer in postmenopausal women: reanalysis of nine prospective studies. J Natl Cancer Inst 2002;94:606-16.

18 Thomas HV, Key TJ, Allen DS, Moore JW, Dowsett M, Fentiman IS, et al. A prospective study of endogenous serum hormone concentrations and breast cancer risk in premenopausal women on the island of Guernsey. Br J Cancer 1997;75:1075-9.

19 Hankinson SE, Willett WC, Colditz GA, Hunter DJ, Michaud DS, Deroo $\mathrm{B}$, et al. Circulating concentrations of insulin-like growth factor-I and risk of breast cancer. Lancet 1998;351:1393-6.

20 Toniolo P, Bruning PF, Akhmedkhanov A, Bonfrer JM, Koenig KI, Lukanova A, et al. Serum insulin-like growth factor-I and breast cancer Int J Cancer 2000;88:828-32.

(Accepted 4 November 2002)

\title{
Controlled trial of effect of documented cardiovascular risk scores on prescribing
}

\author{
L M L Hall, R T Jung, G P Leese
}

Cardiovascular disease causes the death of around $80 \%$ of patients with type 2 diabetes. ${ }^{1}$ However, risk factors for cardiovascular disease in such patients are often untreated $^{2}$ despite the proved benefits of intervention. ${ }^{3}$ One way to help clinicians identify patients at high risk of cardiovascular disease is to use cardiovascular primary prevention risk tables. These tables integrate the multiple risk factors into a single score. We did a pilot study to test the hypothesis that documentation of a cardiovascular risk score in the case notes would improve the management of cardiovascular risk factors.

\section{Participants, methods, and results}

We recruited patients with type 2 diabetes who had no history of cardiovascular disease or renal disease. All patients were aged 35-75 years and attending a hospital outpatient clinic. We recruited 323 patients (167 men and 156 women) attending the clinic consecu- tively. Patients were seen by one of six doctors who were unaware of the ongoing project. We allocated patients alternately to the experimental and control groups (162 experimental, 161 control), and all doctors saw an equal number of experimental and control patients. The University of Dundee special study module subcommittee approved this project on behalf of Tayside Committee on Medical Research Ethics.

We calculated New Zealand cardiovascular risk scores for all patients. ${ }^{5}$ These were clearly documented at the front of the notes of patients in the experimental group only. Standard information, such as weight; glycated haemoglobin, urinary microalbumin, and total and high density lipoprotein cholesterol concentrations; and blood pressure was available for all patients in both groups.

Only 42 patients $(13 \%)$ had a low risk for a cardiovascular event ( $<10 \%$ five year risk), with $113(35 \%)$ having moderate risk (10-20\% risk) and 168 (52\%) a high risk $(>20 \%$ risk $)$. Overall, there were no 
Clinical interventions for patients with type 2 diabetes according to whether their New Zealand cardiovascular risk score was given in the notes

\begin{tabular}{|c|c|c|c|c|}
\hline \multirow[b]{2}{*}{ Intervention } & \multicolumn{2}{|c|}{ All patients } & \multicolumn{2}{|c|}{ High risk patients (>20\% five year risk) } \\
\hline & $\begin{array}{c}\text { No }(\%, 95 \% \text { Cl) of patients } \\
\text { with score }(n=162)\end{array}$ & $\begin{array}{c}\text { No }(\%, 95 \% \mathrm{Cl}) \text { of control } \\
\text { patients }(\mathrm{n}=161)\end{array}$ & $\begin{array}{c}\text { No }(\%, 95 \% \text { Cl) of patients } \\
\text { with score }(n=86)\end{array}$ & $\begin{array}{c}\text { No }(\%, 95 \% \mathrm{CI}) \text { of control } \\
\text { patients }(\mathrm{n}=82)\end{array}$ \\
\hline Change in diabetes treatment & $68(42 \%, 34 \%$ to $50 \%)$ & $58(36 \%, 29 \%$ to $45 \%)$ & $38(44 \%, 35 \%$ to $54 \%)$ & $29(35 \%, 24 \%$ to $47 \%)$ \\
\hline Change in antihypertensive drugs & $26(16 \%, 10 \%$ to $22 \%)$ & $17(10 \%, 5 \%$ to $16 \%)$ & $20 \star(23 \%, 15 \%$ to $31 \%)$ & $8(10 \%, 3 \%$ to $17 \%)$ \\
\hline Change in lipid lowering drugs & $20(12 \%, 7 \%$ to $17 \%)$ & $14(9 \%, 4 \%$ to $14 \%)$ & $17^{\star}(20 \%, 12 \%$ to $27 \%)$ & $7(9 \%, 2 \%$ to $15 \%)$ \\
\hline Referral to dietician & $17(10 \%, 6 \%$ to $15 \%)$ & $21(13 \%, 7 \%$ to $19 \%)$ & $9(10 \%, 5 \%$ to $16 \%)$ & $6(7 \%, 1 \%$ to $17 \%)$ \\
\hline Other & $20(12 \%, 7 \%$ to $17 \%)$ & $15(9 \%, 5 \%$ to $15 \%)$ & $10(12 \%, 6 \%$ to $18 \%)$ & $10(12 \%, 4 \%$ to $20 \%)$ \\
\hline Risk score mentioned in letter to general practitioner & $10(6 \%, 3 \%$ to $10 \%)$ & $3(2 \%,-1 \%$ to $4 \%)$ & $10(12 \%, 6 \%$ to $18 \%)$ & $3(4 \%,-1 \%$ to $8 \%)$ \\
\hline Total No of interventions & 161 & 128 & 104 & 63 \\
\hline
\end{tabular}

${ }^{\star} \mathrm{P}=0.01$ compared with control group by the Mantel-Haenszel test.

significant differences between control and experimental groups in the primary outcome measures (table): change of diabetes treatment $(36 \% v 42 \%)$, lipid lowering drugs $(9 \%$ v 12\%), or blood pressure drugs (10\% v $16 \%)$ and referral to dietician $(13 \% v 10 \%)$. There were no differences in other interventions between the control and experimental groups. Among high risk patients, however, those in the experimental group were more likely to be prescribed blood pressure and lipid lowering drugs than those in the control group $(\mathrm{P}<0.02$, Mantel-Haenszel test). Despite this difference, the time until the next hospital outpatient appointment was the same in the two groups, with $24 \%$ in each group (39 in the experimental group and 38 in the control group) receiving an appointment in less than six months.

\section{Comment}

We found that clear documentation of a cardiovascular risk score in the notes increased prescribing of risk modifying drugs for patients with diabetes who are at high risk of cardiovascular disease. More high risk patients in the experimental group were prescribed both blood pressure lowering and lipid lowering drugs. However, there was no increase in prescribing for patients at relatively low risk.
Although individual risk factors such as blood pressure, smoking status, and lipid concentrations are generally available in clinics, integrated cardiovascular risk scores are often not calculated because of lack of time. This leaves the clinician with complex clinical data that can be difficult to interpret and are thus often not acted on. Our results indicate that it is worth developing clinical support systems that will calculate cardiovascular risk before the consultation.

We thank Dr S Ogston for statistical advice.

Contributors: GPL designed the study, wrote the protocol, and helped to write the paper. LMLH conducted the study and wrote the paper. RTJ helped analyse the data and write the paper.

Funding: None.

Competing interests: None declared.

1 Haffner SM, Lehto S, Ronnemaa T, Pyorala K, Laako M. Mortality from coronary heart disease in subjects with type 2 diabetes and in nondiabetic subjects with and without prior myocardial infarction. $N$ Engl J Med 1998;339:229-34.

2 European Action on Secondary Prevention by Intervention to Reduce Events I and II Group. Clinical reality of coronary prevention guidelines: a comparison of EUROASPIRE I and II in nine countries. Lancet 2001;357:995-1001.

3 United Kingdom Prospective Diabetes Study Group. Tight blood pressure control and risk of macrovascular and microvascular complications in type 2 diabetes (UKPDS 38). BMJ 1998;317:703-13.

4 LaRosa JC, Vupputuri S. Effect of statins on risk of coronary disease: Meta-analysis of randomised controlled trials. JAMA 1999;282:2340-6.

5 Jackson R. Updated New Zealand cardiovascular disease risk-benefit prediction guide. BMJ 2000;320:709-10.

(Accepted 18 April 2002)

\title{
Discrepancies between patients' assessments of outcome: qualitative study nested within a randomised controlled trial
}

\author{
Rona Campbell, Brian Quilty, Paul Dieppe
}

Department of Social Medicine, University of Bristol, Bristol BS8 2PR

Rona Campbell lecturer in health services research

continued over BMJ 2003;326:252-3

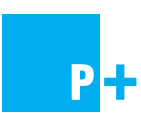

Examples of interviews with patients appear on bmi.com
Assessments of therapeutic effectiveness should not rely exclusively on clinical data, but they should include patient based outcome measures. A plethora of generic and disease specific measures is now available to collect such data by questionnaire, and well developed methods for testing the precision of such measures exist. ${ }^{2}$ Another method of collecting patient based outcome data is by in-depth interview. A randomised controlled trial to test the effectiveness of a package of physiotherapy treatment (nine treatment sessions involving patellar taping, seven different exercises, correction of posture, and advice on footwear) for patellofemoral osteoarthritis, which included a nested qualitative study of 20 participants randomised to the intervention arm, provided an opportunity to compare the two approaches to collecting outcome data: quantitatively by questionnaire and qualitatively by means of in-depth interview. ${ }^{3}$

\section{Participants, methods, and results}

The primary outcome measure was pain in the worse knee, recorded on a $10 \mathrm{~cm}$ visual analogue scale in the presence of $\mathrm{BQ}$. We used the function subscale of the Western Ontario and McMaster Universities' osteoarthritis index (WOMAC), a validated, disease specific, patient based measure, as a secondary outcome measure. ${ }^{5}$ An experienced interviewer undertook the in-depth interviews after the treatment but before the main follow up visit of the trial. Interviews were 